\title{
Intestinal Parasitic Co-Infection in Reaction and Non-Reaction Leprosy Patients of Dhanusha, Nepal
}

\author{
Saurav K. Singh and Mahendra Maharjan \\ Central Department of Zoology, T.U. Kirtipur, Kathmandu, Nepal \\ Email: saurav_singh198638@yahoo.com \& maharjan.m@gmail.com
}

\begin{abstract}
Development of reaction in leprosy patients causes severe complication in treatment. In order to analyze the association between leprosy-reaction and gastrointestinal parasitic co- infection, 100 each leprosy patients with reaction and nonreaction were identified and their stool samples were microscopically examined. The overall frequencies of intestinal parasites observed were 33 percent protozoa and 5.5 percent helminths. Entamoeba histolytica and Giardia lamblia were most prevalent parasites in both group of leprosy-reaction and non-reaction patients. Trichomonas hominis, Strongyloides stercoralis and Ancylostoma duodenales were found only in leprosy-reaction patients. There was positive co-relation between intestinal parasitic co-infection and development of reaction in leprosy patients.
\end{abstract}

Keywords: Parasites, Leprosy, Mycobacterium leprae, Cellular immunity

\section{INTRODUCTION}

Leprosy is a chronic infectious disease caused by the bacteria Mycobacterium leprae and M. lepromatosis. $M$. leprae is a non-motile, non-spore forming, microaerophilic, acid-fact staining bacterium that usually forms slightly curved or straight rods (Daffe et al. 1993, Vissa \& Brennan 2001). Macrophages and peripheral nerves (especially Schwann cells) are the prime infection target of this pathogen. Once established in tissue, $M$. leprae colonization and immunological reactions to its antigens can cause enlarged thickened peripheral nerves and sensory neuropathy, cutaneous lesions, disfigurement and severe disability (Robbins 2009).

Leprosy-reactional episodes (REs) are serious complications of leprosy. During the course of leprosy 16-56 percent of patient develop irreversible nerve function impairment (Britton \& Lockwood 2004) caused by the leprosy-reaction. Substantial fractions of leprosyreaction $(30-40 \%)$ are diagnosed concurrently with leprosy (Scollard et al. 1994, Ranque et al. 2007), which could partially explain the persistent detection of severe disability at the leprosy diagnosis (Pannikar 2009). Chronic intestinal parasitic infections have become the subject of speculation and investigation in relation to the spreading and severity of infectious diseases such as leprosy, tuberculosis and HIV/AIDS (Bentwich et al. 1995, Diniz et al. 2001, Co et al. 2007). The recent study suggested that a pre-existing infection by intestinal helminthes may facilitate the establishment of $M$. leprae and M. tuberculosis infection or its progression to more severe form of disease (Stewart et al. 1999, Co et al. 2007, Diniz et al. 2010).
Leprosy-reaction episodes are increasing in Nepal and posing a serious complication in treatment. This study focuses on linkage between development of reaction in leprosy patients with the intestinal parasitic infection in between reaction and non-reaction leprosy patients at Lalgadh Leprosy Service Centre (LLSC), Dhanusa, Nepal.

\section{MATERIALS AND METHODS}

The study was designed to assess the association between leprosy-reaction and parasitic co-infection using purposive sampling method. Leprosy-reaction and non-reaction patients were differentiated by the leprosy expert (Dermatologist) of LLSC, Dhanusha.

A total of 200 leprosy patients, 100 each from reaction and non-reaction visiting at LLSC, Dhanusha during the year 2011-2012 were included in this study. The fresh morning stool samples provided by the patients were microscopically examined using direct smear technique at the laboratory of LLSC. For the further confirmation, positive samples were re-examined at parasitology laboratory Central Department of Zoology. The parasites found in both leprosy-reaction and non-reaction patients were compared.

\section{RESULTS}

The prevalence of intestinal parasitic infection was higher in reaction leprosy patients $(51 \%)$ than nonreaction leprosy patients $(26 \%)$. The protozoan parasitic infection was seen frequent in both reaction and nonreaction leprosy patients than helminths (Fig. 1). 


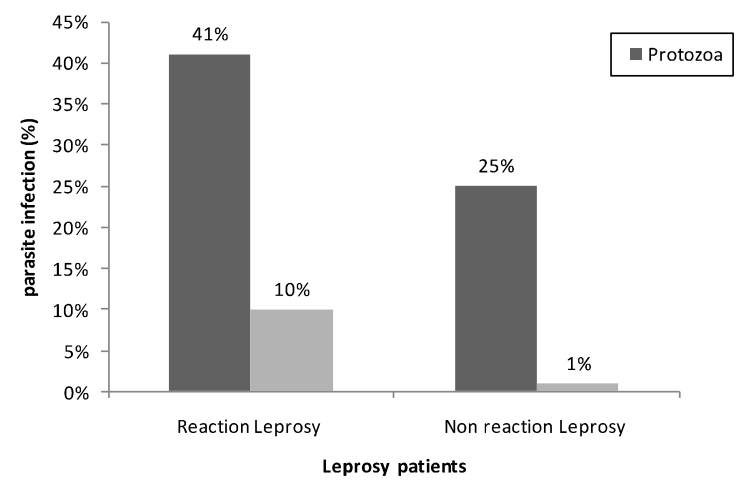

Co-infection of Entamoeba histolytica (20\%) in leprosy patients was high than other parasites but Hymenolepis nana was recovered from single patient of each in reaction and non-reaction leprosy. Trichomonas hominis, Ancylostoma duodenale and Strongyloides stercoralis were found in only reaction leprosy patients. Parasitic co-infection in both male (39\%) and female (37\%) was almost same (Table 1).

Fig. 1. Prevalence of intestinal parasites in leprosy patients

Table 1. Comparison of specific intestinal parasites in leprosy patients

\begin{tabular}{|c|c|c|c|c|c|c|c|}
\hline \multirow[t]{2}{*}{ Parasites } & \multicolumn{3}{|c|}{ Leprosy-reaction patients $(\mathrm{N}=100)$} & \multicolumn{3}{|c|}{$\begin{array}{l}\text { Non-reaction leprosy patients } \\
(\mathbf{N}=100)\end{array}$} & \multirow{2}{*}{$\begin{array}{c}\text { Total }(\mathrm{N}=200) \\
\text { No .of parasites }\end{array}$} \\
\hline & $\mathbf{M}(\%)$ & $\mathbf{F}(\%)$ & Total(\%) & M (\%) & $\mathbf{F}(\%)$ & Total(\%) & \\
\hline E. histolytica & 13 & 12 & 25 & 11 & 5 & 16 & $41(20.5 \%)$ \\
\hline G. lamblia & 6 & 2 & 8 & 4 & 5 & 9 & $17(8.5 \%)$ \\
\hline T. hominis & 4 & 4 & 8 & 0 & 0 & 0 & $8(4 \%)$ \\
\hline \multicolumn{8}{|l|}{ Nematoda } \\
\hline A. duodenales & 3 & 1 & 4 & 0 & 0 & 0 & $4(2 \%)$ \\
\hline S. stercoralis & 2 & 3 & 5 & 0 & 0 & 0 & $5(2.5 \%)$ \\
\hline \multicolumn{8}{|l|}{ Cestoda } \\
\hline H. nana & 1 & 0 & 1 & 1 & 0 & 1 & $2(1 \%)$ \\
\hline
\end{tabular}

\section{DISCUSSION AND CONCLUSION}

Leprosy-reactions are characterized by an intense and sudden activation and reactivation of host immune responses that frequently affect the peripheral nerves. The clinical manifestations of leprosy-reactions are an acute inflammation of pre-existing lesions which can become erythematous, oedematous and infiltrated. Development of reaction in leprosy patients is still not well understood. Some studies have shown the association of protozoan as well as helminth parasites and development of reaction in leprosy patients (Dolo et al. 2002, Diniz et al. 2010).

Leprosy patients were found to be infected with six different species of protozoan and helminth intestinal parasites. The intestinal parasites observed in the study include 3 species of protozoa i.e. E. histolytica, Giardia lamblia and T. hominis and 3 species of helminths i.e. A. duodenale, $S$. stercoralis and $H$. nana. The frequently observed protozoan parasites were E. histolytica (25\%) in reaction leprosy patients and $(16 \%)$ in non-reaction leprosy patients, as well as G. lamblia (8\%) in reaction leprosy patients and $(9 \%$ in non-reaction leprosy patients. Both E. histolytica and G. lamblia were not found to be associated with the development of leprosy-reaction. while, an intestinal commensal flagellate parasite, $T$. hominis, was observed only in reaction leprosy patients with each $(4 \%)$ infection in male and female. However this parasite was not reported from leprosy patients so far earlier. The presence of this parasite assumed that it might possess certain immuno-modulatory mechanism in the host, which favours the growth of $M$. leprae infection to more severe form of the disease. Therefore further investigation is required to understand the immunopathology of this intestinal parasite.

Helminths infection, particularly the nematodes which include $A$. duodenales (4\%) and S. stercoralis $(5 \%)$ were found only in reaction leprosy patients when compared to non-reaction leprosy patients. These findings are similar to that of earlier results of Diniz et al. (2010) in which helminth co-infection has shown in lepromatous leprosy patients.

Among the Cestodes only H. nana was found with infection of $(1 \%)$ in each leprosy-reaction and nonreaction patients. However this parasite is not reported from other studies. Nematodes were more prevalent than Cestodes which is supported by the previous studies of nematode co-infection in leprosy patients (Diniz et al. 2001) and prevalence of $A$. duodenales in leprosy patients (Dolo et al. 2002). The present study did not reveal other 
nematodes like A. lumbricoides and T. trichiura in either of the leprosy-reaction or non-reaction patients, but reported by other studies (Hong et al. 1983, Diniz et al. 2001, 2010).

In this study, overall helminths infection was higher (5\%) in reaction leprosy patients compared to non- eaction leprosy patients. This study suggested that intestinal helminthes parasitic co-infection might have intervened with the normal immune response to mycobacterial infection (Stewart et al. 1999) and the possibility of an existing infection with intestinal helminths may facilitate a subsequent infection with $M$. leprae (Abulafia \& Vignale 1999, Goulart et al. 2002, Co et al. 2007).

The prevalence of $S$. stercoralis infection was higher in reaction leprosy patients indicating helminths coinfection in lepromatous leprosy patients (Diniz et al. 2010). Leprosy-reaction and Strongyloides co-infection was found to be intimately associated as shown by previous observations (Leang et al. 2004 and Corti et al. 2011). S. stercoralis infection were observed from those reaction patients who were subjected to prolonged immunosuppressive therapy of steroids (prednisolone), regardless of drug dosages, which further support the study regarding S. stercoralis hyperinfection syndrome in leprosy patients subjected to immunosuppressive therapy of steroids (Hagelskjaer 1994, Leang et al. 2004 and Corti et al. 2011). As S. stercoralis infection was observed higher in leprosy-reaction patients, such patients should be diagnosed early because it has huge mortality rate of about $87 \%$ (Leang et al. 2004), therefore prevention is utmost important. Also A. duodenale infestation in reaction patients was $4 \%$ and is supported by its presence in leprosy patients through previous demonstration (Dolo et al. 2002, Diniz et al. 2010).

Intestinal parasitic co-infection particularly with $S$. stercoralis and $A$. duodenale (helminths) as well as T. hominis (protozoa) in leprosy patients may have influenced in development of reaction in leprosy patients. Hence further investigation is required to understand the immunopathology of these parasites, in the case of reaction leprosy patients.

\section{ACKNOWLEDGEMENTS}

Authors are highly grateful to the Lalgadh Leprosy Service Centre, Dhanusa specially to Dr. Graeme A Clungston for his support to differentiate reaction and non-reaction leprosy patients. Similarly we are thankful to Damber Bahadur Ale for his help during the sample collection and processing.

\section{REFERENCES}

Abulafia, J. and Vignale, R.A. 1999. Leprosy: pathogenesis updated. International Journal of Dermatology 38: 321-324.

Bentwich, Z., Kalinkovich, A. and Weisman, Z. 1995. Immune activation is a dominant factor in the pathogenesis of African AIDS. Immunology Today 16: 187-191.

Britton, W.J. and Lockwood, D.N. 2004. Leprosy. Lancet 363: 1209-1219.

Corti, M., Villafane M.F., Trione, N., Risso, D., Abuin, J.C. and Palmieri, O. 2011. Infection due to Strongyloides stercoralis: epidemiological, clinical, diagnosis findings and outcome in 30 patients. Revista de Chilena Infectologia 3: 217 222.

Co, T.R., Hirsch, C., Toossi, Z., Dietze, R. and RibeiroRodrigues, R. 2007. Intestinal helminth coinfection has a negative impact on both antimycobacterium tuberculosis immunity and clinical response to tuberculosis therapy. Clinical and Experimental Immunology 147: 45-52

Daffe,M.,McNeil,M.,Brennan,P.J. 1993. Majorstructural features of the cell wall arabinogalactans of Mycobacterium, Rhodococcus and Nocardia spp. Carbohydrate Research 249(2): 383-398.

Diniz, L.M., Malgalhaes, E.F.L., Pereira, F.E.L., Dietze, R. and Rodrigues, R.R. 2010. Presence of intestinal helminths decreases $\mathrm{T}$ helper type 1 responses in tuberculoid leprosy patients and may increase the risk for multi-bacillary leprosy. Clinical and Experimental Immunology 161: 142-150.

Diniz, L.M., Zandonade, E., Dietze, R, Pereira, F.E.L. and Rodrigues, R.R. 2001. Short report: do intestinal nematodes increase the risk for multibacillary leprosy? American Journal of Tropical Medicine and Hygiene 65: 852-854.

Dolo, A., Diane, K., Coulibaly, I., Sow, S., Konare Diawara, H., Fomba, A., Thera, M.A., diallo, A., Keita, S., Doumbo, O. 2002. Systematic search for parasites among leprosy patients in Mali. Medicine Tropicale 62(5): 503-506.

Goulart, I.M.B., Penna, G.O. and Cunha, G. 2002. Immunopathology of Leprosy: the complexity of the host's immune response to Mycobacterium leprae. Revista do Sociedade Brasileira de Medicina Tropica 35(4): 365-375. 
Hagelskjaer L.H. 1994. A fatal case of systemic strongyloidiasis and review of the literature. European Journal of Clinical Microbiology and Infectious Diseases. 13(12): 1069-1074.

Hong, S.T., Hong, S.J., Lee, S.H., Kim, I.S. and Shin, J.S. 1983. A Study on the intestinal helminths of the patients in a leprosarium in Korea. Kisaengchunghak Chapchi 1: 102-104.

Leang, B., Lynen, L., Tootill, R., Griffiths, S. and Monchy, D. 2004. Death caused by Strongyloides hyper infection in a leprosy patient on treatment for a type 2 leprosy-reactions. Leprosy Review 75(4): 398-403.

Pannikar, V. 2009. Enhanced global strategy for further reducing the disease burden due to leprosy: 2011- 2015. Leprosy Review 80: 353- 354.

Ranque, B., Nguyen, V. T., Vu, H.T., Nguyen, T. H., Nguyen, N.B., Pham, X.K., Schurr, E., Abel, L. and Alcais, A. 2007. Age is an important risk factor for onset and sequeale of reversal reactions in Vietnamese patients with leprosy. Clinical Infectious Disease 44(1): 33-40.
Robbins, G., Tripathy, V.M., Misra, V.N., Mohanti, R.K., Syndhey, V.S. 2009. Ancient skeletal evidence for leprosy in India. PLoS ONE 4(5): e 5669

Scollard, D.M., Smith, T., Bhoopati, L., Theetranont, C., Rangdaeng, S., Morens, D.M. 1994. Epidemiologic characteristics of leprosyreactions. International Journal of Leprosy $\mathbf{6 5}$ : 559-567.

Stewart, G.R., Boussinesq, M., Coulson, T., Elson, L., Nutman, T. and Bradley, J.E. 1999. Onchocerciasis modulates the immune response to mycobacterial antigens. Clinical and Experimental Immunology 117: 517-523.

Vissa, V.D. and Brennan, P.J. 2001. The genome of Mycobacterium leprae: a minimal mycobacterial gene set. Genome Biology 2(8): 1023. 